Available online at GSC Online Press Directory

GSC Biological and Pharmaceutical Sciences

e-ISSN: 2581-3250, CODEN (USA): GBPSC2

Journal homepage: https://www.gsconlinepress.com/journals/gscbps

(RESEARCH ARTICLE)

\title{
Microbiological assessment of environmental surfaces in a healthcare facility
}

\author{
Amaka M Awanye * and Believe Amrasawore \\ Department of Pharmaceutical Microbiology and Biotechnology, Faculty of Pharmaceutical Sciences, University of Port \\ Harcourt, Nigeria.
}

Publication history: Received on 22 July 2020; revised on 05 August 2020; accepted on 06 August 2020

Article DOI: https://doi.org/10.30574/gscbps.2020.12.2.0236

\begin{abstract}
Hospital-acquired infections (HAIs) are infections occurring within 48 hours of hospital admission, 3 days of hospital discharge or 30 days after a surgical procedure. HAIs are a major cause of death and disability within the hospital. Inanimate surfaces can serve as sources of HAIs and can significantly contribute to the spread of pathogens within hospitals. Swab samples were obtained from 53 inanimate surfaces such as air, bed pan, ward doorknob, nurses' glove, sink, sink tap, cistern lever, toilet seat and wheel chairs located in the various wards of the Accident and Emergency Unit as well as Plastic and Burn unit of, University of Port Harcourt Teaching Hospital (UPTH). The samples obtained were screened for the presence of pathogenic microorganisms and their susceptibility to frequently prescribed antibiotics using disc diffusion method. Our findings showed highest level of contamination was the cistern lever (15\%), and the least was from nurses' gloves (6\%). Microbial identification revealed the presence of 161 microorganisms comprising Pseudomonas aeruginosa (27 \%), Staphylococcus spp. (22\%), Salmonella spp. (16\%), Klebsiella spp. (13 \%), and Candida spp. (21\%). Interestingly, $83 \%$ of isolated staphylococci were resistant to cefoxitin, $57 \%$ of Pseudomonas spp. was resistant to levofloxacin, and both Klebsiella spp. and Salmonella spp. were most resistant to ceftriaxone (81\% and 77 $\%$ respectively). The observed high prevalence of pathogenic and antibiotic resistant microorganisms calls for implementation of regular surveillance and effective infection control measures within the hospital.
\end{abstract}

Keywords: Nosocomial Infections; Hospital-Acquired Infections; Inanimate Surfaces; Fomites; Antimicrobial Resistance

\section{Introduction}

Hospital-acquired infections (HAIs) also known as nosocomial infections or healthcare-acquired infections are those infections that were acquired while receiving care in a hospital or healthcare facility. They include infections that occur after 48 hours of hospital admission, within 30 days of a surgical operation, 3 days after discharge from a hospital, and infections that arise other than the primary cause of hospitalization (1). HAIs are major causes of mortality and morbidity in hospitals. It has been reported that HAIs caused by resistant microorganisms increase the cost of treatment, duration of treatment, and mortality rate (2). The hospital environment especially the accident and emergency unit is a major source of infection. This is because people with various medical-related emergencies and health conditions first present to this unit before they are transferred to the appropriate department for treatment. Patients with burn injuries are at higher risk of opportunistic infections due to the loss of skin, a protective barrier to infection. Bacterial infections in patients with burn injuries increases the risk of mortality (3). The hospital environment is predisposed to harbour microorganisms considering the traffic of patients, patient-care activities performed by healthcare providers and the medical equipment used that will require frequent cleaning. Despite routine cleaning, many studies have revealed the presence of opportunistic pathogens including resistant strains in many inanimate surfaces in the hospital (4-10). Many pathogens that are involved in HAIs are harboured on inanimate surfaces. They are able to form biofilms that protect them from clearance by disinfectants.

\footnotetext{
* Corresponding author: Awanye Amaka M
} 
Antimicrobial resistance (AMR) has become a huge global challenge as microorganisms have developed resistance to virtually all antibiotics available. AMR increases duration and cost of treatment, reduces therapeutic outcome, reduces quality of life and increases mortality (11). Many multi-drug resistant pathogens have been identified and are implicated in many hospital-acquired infections (12). The Plastic and Burn Unit as well as Accident and Emergency unit frequently have patients in critical conditions that are more at risk of contracting infections caused by antimicrobial resistant pathogens. Hence, it is imperative that while receiving care in a hospital, that patients do not encounter pathogens that may cause opportunistic infections and complicate their already existing medical condition. Identifying inanimate sites that harbour anti-microbial resistant pathogens and the common microbial contaminants may be pivotal to the promotion and implementation of effective infection control practices within the University of Port Harcourt Teaching Hospital (UPTH).

\section{Material and methods}

\subsection{Study site}

The study was carried out in the various wards of the accident and emergency and plastic and burn units of University of Port Harcourt Teaching Hospital (UPTH) Port Harcourt, Nigeria.

\subsection{Sample collection}

Samples were collected from inanimate surfaces or fomites such as air, clean patient's bed pan, ward doorknob, nurses' gloves, sink, sink tap, cistern lever, toilet seat and wheel chairs located in the selected wards. A description is shown in Table 1 . The samples were obtained by rubbing sterile swabs sticks pre-soaked in $0.9 \%$ physiological saline on the inanimate surfaces $(5 \mathrm{~cm} \times 5 \mathrm{~cm}$ ). The swabs sticks were replaced into the collection tubes and labeled appropriately. All samples were then transported to the research laboratory and inoculated in $5 \mathrm{ml}$ nutrient broth (for bacterial isolation) and Sabouraud dextrose broth (for fungal isolation) within 6 hours of sample collection. Bacterial cultures were grown at $37{ }^{\circ} \mathrm{C}$ for 24 hours and $25{ }^{\circ} \mathrm{C}$ for 48 hours for fungal cultures. Exposing sterile nutrient agar and Sabouraud dextrose agar plates for 10-15 minutes collected air samples.

\subsection{Microbial isolation and identification}

All samples were cultured on selective and differential media such as cetrimide agar, mannitol salt agar, MacConkey agar and, Salmonella-Shigella agar (Titan, India) and incubated at $37^{\circ} \mathrm{C}$ for 24 hours for bacterial growth. Fungal culture plates were grown on Sabouraud dextrose agar (SDA) for $1-3$ days at $25^{\circ} \mathrm{C}$. The microbes were identified according to the Clinical and Laboratory Standards Institute (CLSI) guidelines $(13,14)$. Species identification was based on colony morphology, Gram staining, microscopy and biochemical testing.

\subsection{Antibacterial susceptibility testing}

Determination of susceptibility of bacterial isolates to commonly prescribed antibiotics was evaluated using the KirbyBauer agar diffusion assay (15). In brief, bacterial inoculum is standardized with peptone water to match $0.5 \mathrm{McFarland}$ solution. A $0.1 \mathrm{ml}$ volume of standardized bacterial culture was spread on sterile Mueller Hinton Agar plate. Using sterile forceps, single antibiotic discs (Oxoid, UK) namely gentamicin (10 $\mu \mathrm{g})$, amoxicillin/clavulanate (30 $\mu \mathrm{g})$, doxycycline (30 $\mu \mathrm{g})$, levofloxacin $(5 \mu \mathrm{g})$, clindamycin $(2 \mu \mathrm{g})$, erythromycin $(15 \mu \mathrm{g})$, cefoxitin $(30 \mu \mathrm{g})$ and ceftriaxone $(30 \mu \mathrm{g})$ were placed on the surface of the agar and incubated at $37^{\circ} \mathrm{C}$ for 24 hours. After incubation, the clear zones of inhibition around the discs were measured and the degree of susceptibility was determined based on the guidelines recommended by CLSI $(13,14)$.

\section{Results}

\subsection{Microbial distribution profile on fomites}

A total of 53 swab samples were collected from 9 different inanimate collection sites in the 7 wards of the burn unit and accident and emergency wards of UPTH (Table 1). As shown in Table 2, microbial culture and identification revealed a total of 161 microbial isolates (127 bacterial isolates and 34 fungal isolates) from all 53 fomites. The microbes isolated from all wards include Pseudomonas spp. (44), Klebsiella spp. (21), Staphylococcus spp. (36), Salmonella spp. (26) and Candida spp. (34). Most wards had high levels of contamination and most sites showed evidence of poly-microbial contamination. More microbes were isolated from the general wards of the accident and emergency unit: 31 (19\%) each from the male and female wards, 23 (14\%) from the resuscitation ward and the least number 7 (4 \%) were from 
the theatre. In the burn unit, 33 (20\%) microbes were isolated from the female ward, 25 (15\%) from the male ward and 15 (9\%) from the children's ward.

Table 1 Sample collection sites from various wards in the accident and emergency and plastic and burn units of UPTH

\begin{tabular}{|c|c|c|c|c|c|c|c|c|}
\hline \multirow[b]{2}{*}{ Collection site } & \multicolumn{4}{|c|}{ Accident and emergency unit } & \multicolumn{3}{|c|}{ Plastic and burn unit } & \multirow[b]{2}{*}{$\begin{array}{l}\text { Total } \\
\text { Samples }\end{array}$} \\
\hline & $\begin{array}{l}\text { Male } \\
\text { ward }\end{array}$ & $\begin{array}{l}\text { Female } \\
\text { ward }\end{array}$ & $\begin{array}{l}\text { Resuscitation } \\
\text { ward }\end{array}$ & Theatre & $\begin{array}{l}\text { Male } \\
\text { ward }\end{array}$ & $\begin{array}{l}\text { Female } \\
\text { ward }\end{array}$ & $\begin{array}{l}\text { Children's } \\
\text { ward }\end{array}$ & \\
\hline Air & + & + & + & + & + & + & + & 7 \\
\hline Bed pan & + & + & + & - & + & + & - & 5 \\
\hline Cistern lever & + & + & + & + & + & + & + & 7 \\
\hline Doorknob & + & + & + & + & + & + & + & 7 \\
\hline Nurses' gloves & + & + & + & - & - & - & - & 3 \\
\hline Sink & + & + & + & + & + & + & + & 7 \\
\hline Sink tap & + & + & + & + & + & + & + & 7 \\
\hline Toilet seat & + & + & + & + & + & + & + & 7 \\
\hline Wheel chair & + & + & + & - & - & - & - & 3 \\
\hline Total & 9 & 9 & 9 & 6 & 7 & 7 & 6 & 53 \\
\hline
\end{tabular}

(+): Sample collected; (-): No sample collected

Table 2: Distribution profile of microbes isolated from the various fomites

\begin{tabular}{|c|c|c|c|c|c|c|c|c|}
\hline & \multicolumn{4}{|c|}{ Accident and emergency unit } & \multicolumn{3}{|c|}{ Plastic and burn unit } & \multirow{2}{*}{$\begin{array}{l}\text { Total } \\
\text { isolates }\end{array}$} \\
\hline & Male & Female & Resuscitation & Theatre & Male & Female & Children's & \\
\hline \multicolumn{9}{|c|}{ Staphylococcus spp. } \\
\hline Air & + & + & + & - & - & + & - & 4 \\
\hline Bed pan & + & + & - & - & - & + & - & 3 \\
\hline Cistern lever & + & + & + & - & - & + & - & 5 \\
\hline Doorknob & + & + & + & - & + & + & + & 6 \\
\hline Nurses' gloves & + & + & + & - & - & - & - & 3 \\
\hline Sink & + & + & - & - & + & + & + & 4 \\
\hline Sink tap & + & + & - & - & - & + & - & 4 \\
\hline Toilet seat & + & + & + & - & + & + & - & 4 \\
\hline Wheel chair & + & + & + & - & - & - & - & 3 \\
\hline Total isolates & 9 & 9 & 6 & 0 & 3 & 7 & 2 & 36 \\
\hline \multicolumn{9}{|l|}{ Salmonella spp. } \\
\hline Air & - & - & - & - & - & + & - & 1 \\
\hline Bed pan & + & + & - & - & + & + & - & 4 \\
\hline Cistern lever & + & - & - & - & - & + & + & 3 \\
\hline Doorknob & + & - & - & + & + & + & - & 4 \\
\hline Nurses' gloves & + & + & - & - & - & - & - & 2 \\
\hline Sink & + & - & - & - & + & + & + & 4 \\
\hline
\end{tabular}




$\begin{array}{lllllllll}\text { Sink tap } & + & - & - & - & - & + & + & 3 \\ \text { Toilet seat } & + & - & - & - & + & + & + & 4 \\ \text { Wheel chair } & + & - & - & - & - & - & - & 1 \\ \text { Total isolates } & 8 & 2 & 0 & 1 & 4 & 7 & 4 & 26 \\ \text { Pseudomonas spp. } & & & & & + & & & \\ \text { Air } & - & - & + & + & + & + & + & 5 \\ \text { Bed pan } & + & + & + & - & + & + & - & 5 \\ \text { Cistern lever } & + & + & - & + & + & + & + & 6 \\ \text { Doorknob } & - & + & - & + & + & + & - & 4 \\ \text { Nurses' gloves } & + & + & - & - & - & - & - & 2 \\ \text { Sink } & + & + & + & + & + & + & + & 7 \\ \text { Sink tap } & + & + & + & + & + & + & + & 7 \\ \text { Toilet seat } & + & + & - & + & + & + & - & 5 \\ \text { Wheel chair } & + & + & + & - & - & - & - & 3 \\ \text { Total isolates } & 7 & 8 & 5 & 6 & 7 & 7 & 4 & 4\end{array}$

Klebsiella spp.

Air

Bed pan

Cistern lever

Doorknob

Nurses' gloves

Sink

Sink tap

Toilet seat

Wheel chair

Total isolates

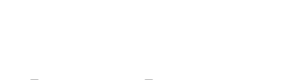

Candida spp.

Air

Bed pan

Cistern lever

Doorknob

Nurses' gloves

Sink

Sink tap

Toilet seat

Wheel chair

Total isolates
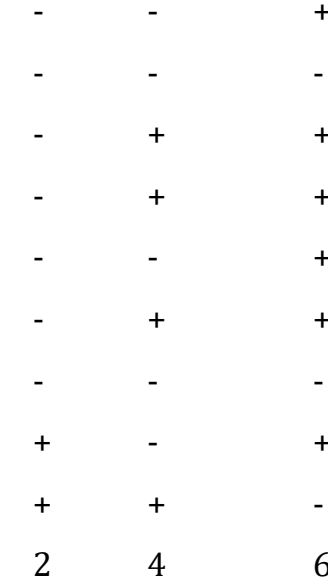

2

2

4

Frequency

$5 \quad 8$

31

6

0

5

Relative frequency (\%)

14

4

$15 \quad 20$

9


Following the results obtained as presented in Table 3, it shows that Pseudomonas spp. was the most prevalent microbe isolated (27\%), followed by Staphylococcus spp. (22\%), Candida spp. (21\%), Salmonella spp. (16 \%) and the least was Klebsiella spp. (13\%). Pseudomonas spp. unlike other microbes isolated was obtained from every ward including the theatre in the accident and emergency unit (Table 2). Our findings also show that the toilet area poses the highest risk of nosocomial infection and that the highest number of microbial pathogens were isolated from the cistern lever (15\%) followed by toilet seat (14\%), sink (14\%), sink tap (12\%) and door knob (12\%). The least number of microbes were isolated from nurses' gloves (6\%).

Table 3: Relative frequency of occurrence of isolates

\begin{tabular}{lrrrrrrr}
\hline & $\begin{array}{r}\text { Staphyloc } \\
\text { occus spp. }\end{array}$ & $\begin{array}{r}\text { Salmonel } \\
\text { la spp. }\end{array}$ & $\begin{array}{r}\text { Pseudomo } \\
\text { nas sp. }\end{array}$ & $\begin{array}{r}\text { Klebsie } \\
\text { Ila spp. }\end{array}$ & $\begin{array}{r}\text { Candida } \\
\text { spp. }\end{array}$ & $\begin{array}{r}\text { Total } \\
\text { frequency } \\
\text { (N) }\end{array}$ & $\begin{array}{r}\text { Relative } \\
\text { frequency } \\
\text { (\%) }\end{array}$ \\
\hline Air & 4 & 1 & 5 & 2 & 3 & 15 & 9 \\
Bedpan & 3 & 4 & 5 & 2 & 2 & 16 & 10 \\
Cistern lever & 5 & 3 & 6 & 4 & 6 & 24 & 15 \\
Doorknob & 6 & 4 & 4 & 3 & 3 & 20 & 12 \\
Nurses' gloves & 3 & 2 & 2 & 1 & 2 & 10 & 6 \\
Sink & 4 & 4 & 7 & 3 & 5 & 23 & 14 \\
Sink tap & 4 & 3 & 7 & 1 & 4 & 19 & 12 \\
Toilet seat & 4 & 4 & 5 & 3 & 6 & 22 & 14 \\
Wheel chair & 3 & 1 & 3 & 2 & 3 & 12 & 7 \\
\hline Total microbes isolated & 36 & 26 & 44 & 21 & 34 & 161 & 100 \\
Relative frequency of & & & & & & & 100 \\
microbial isolation (\%) & 22 & 16 & 27 & 13 & 21 & & \\
\hline
\end{tabular}

\subsection{Antibiogram profile of isolated bacteria}

Antibacterial susceptibility testing carried out on all bacteria isolated from various fomites showed varying degrees of susceptibility to commonly prescribed antibiotics (Fig. 1). Isolated staphylococci showed highest level of sensitivity to levofloxacin (66\%) followed by gentamicin (60\%), doxycycline (40\%), erythromycin (20\%), and clindamycin (20\%). Interestingly, $83 \%$ of isolated Staphylococcus spp. was resistant to cefoxitin, indicating the presence of methicillin resistant Staphylococcus aureus. The susceptibility of isolated Pseudomonas spp. to the 2 anti-pseudomonal drugs tested showed a higher level of susceptibility to levofloxacin (41\%) than gentamicin (25\%). Both Klebsiella spp. and Salmonella spp. showed high levels of resistance against amoxicillin/clavulanate, doxycycline, levofloxacin and ceftriaxone. The highest level of resistance in Klebsiella spp. and Salmonella spp. was recorded for ceftriaxone, $81 \%$ and $77 \%$ respectively. And both Enterobacteriaceae were most sensitive to gentamicin $52 \%$ and $50 \%$ respectively.

The antibiotic susceptibility pattern for every bacterium isolated from the sampled fomites showed a diverse distribution pattern (Fig. 2). The highest amount of resistant bacteria were isolated from bed pans (69\%), followed by cistern lever (62\%), toilet seats (58\%), door knobs (54\%), nurses' gloves (46\%), wheel chair (46\%), air (45\%), sink (43\%) and least from sink tap (40\%). Conversely, the sink tap (48\%) harboured more susceptible bacterial that the bedpan $(21 \%)$. 

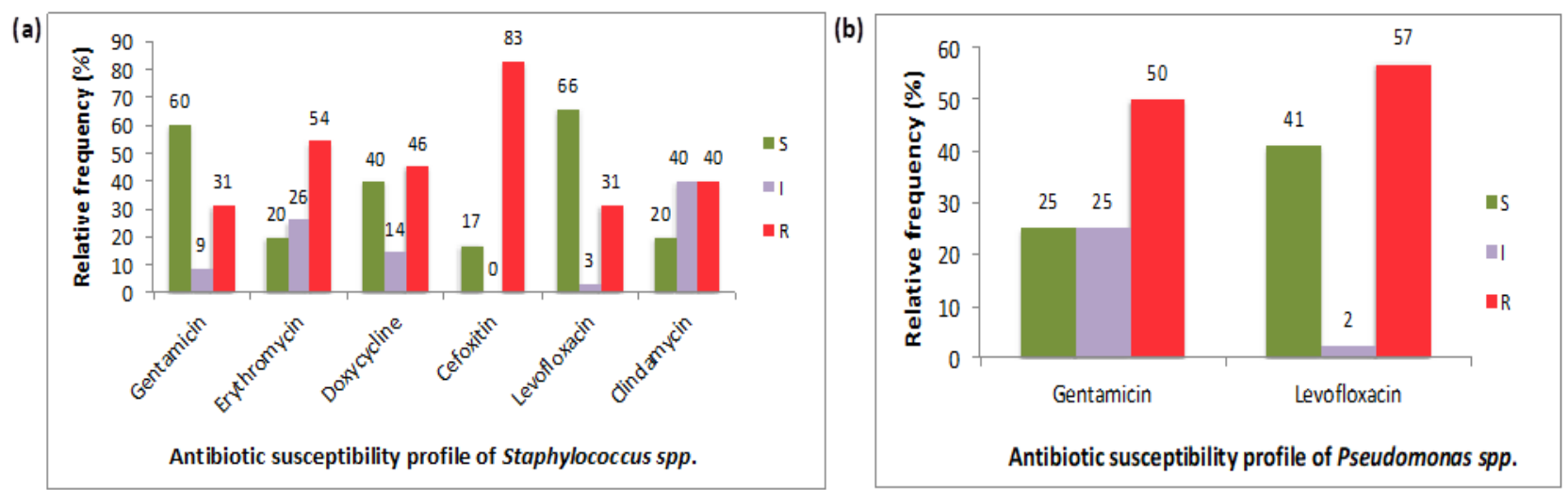

(c)

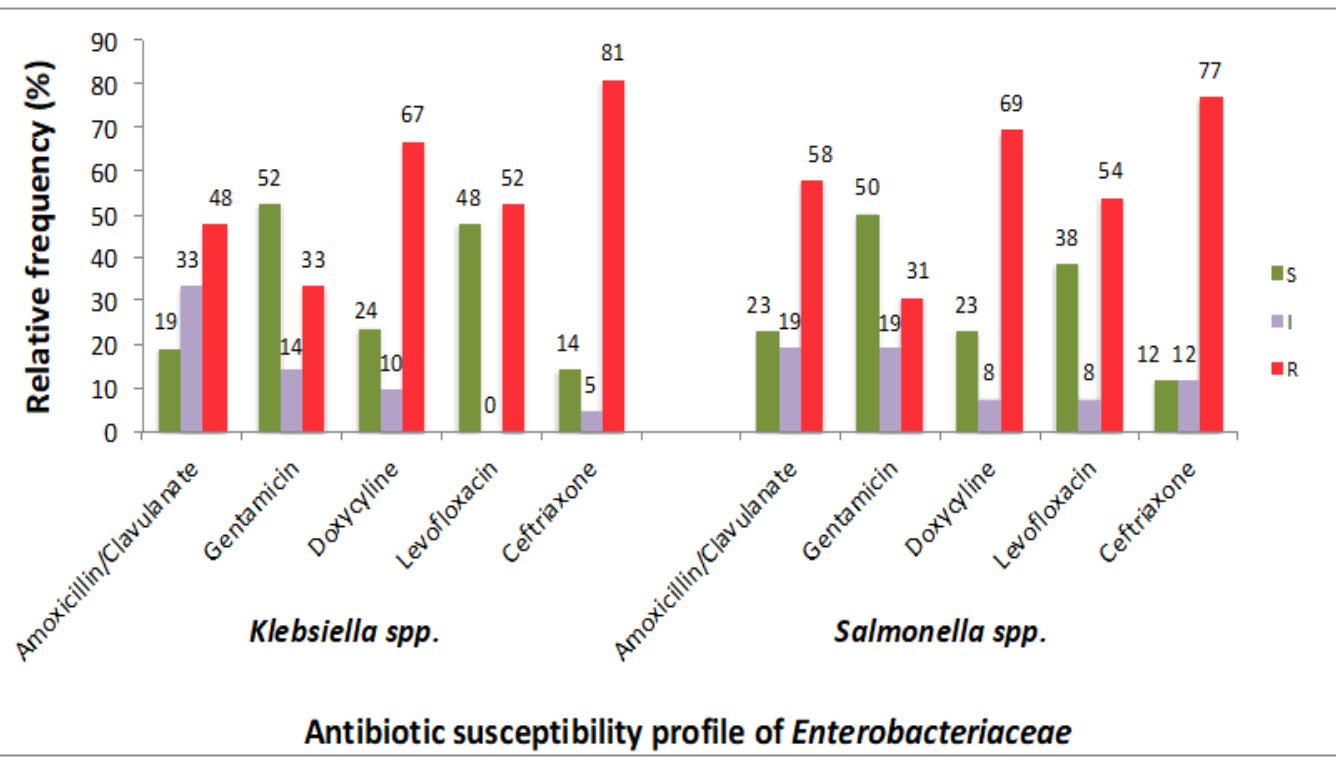

Figure 1: Antibiotic susceptibility pattern of isolated bacteria. Test was carried out using the disc diffusion method and susceptibility cut-offs used were in accordance with the recommendation by CLSI. All tests were performed in duplicates. S: sensitive; I: intermediate susceptibility; R: resistance.

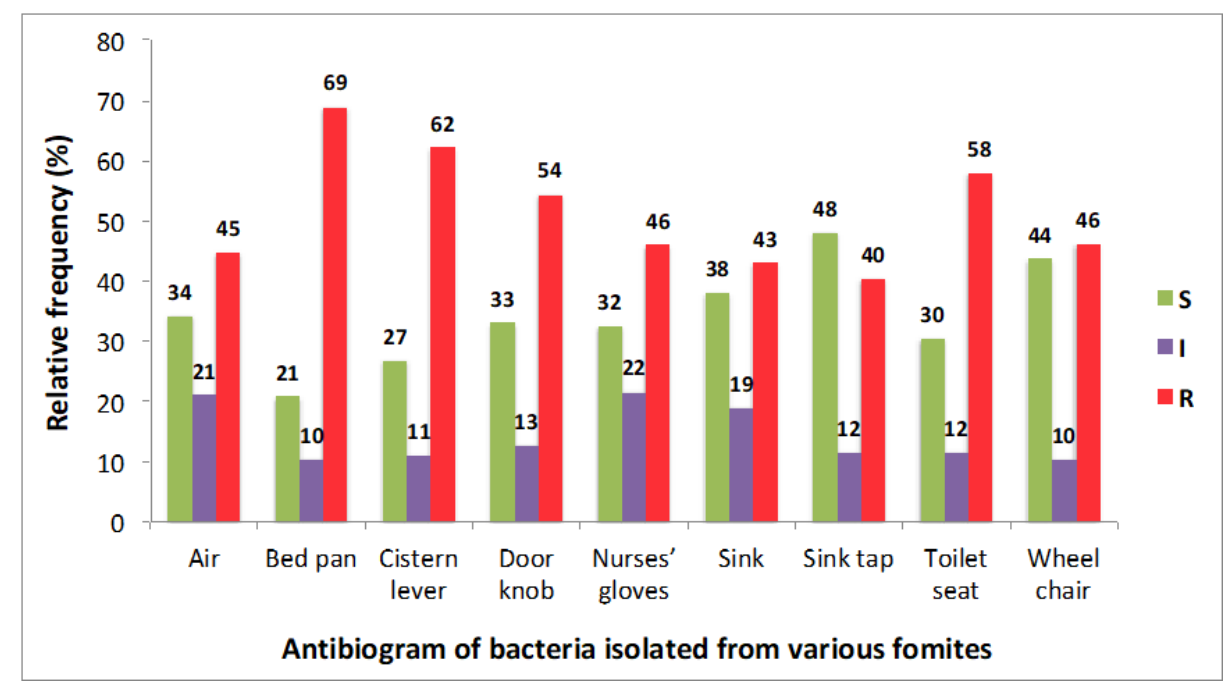

Figure 2: Antibiogram of bacteria isolated from fomites in various wards of accident and emergency wand plastic and burn units of UPTH. S: sensitive; I: intermediate susceptibility; R: resistance. 


\section{Discussion}

Despite good infection control practices employed in the hospital, our findings revealed the presence and prevalence of pathogenic microorganisms in various fomites at the Accident and Emergency Unit and Plastic and Burn Unit of University of Port Harcourt Teaching Hospital. Different pathogenic bacteria and fungi from various fomites were obtained from all wards sampled. The study showed more contaminated surfaces in the Accident and Emergency Unit than the Plastic and Burn Unit. The higher incidence of contaminated fomites in the Accident and Emergency Unit may be attributed to high patient traffic, rapid patient turnover and even overcrowding compared to the Plastic and Burn Unit. Pathogenic microorganisms isolated from the 53-screened fomites include: Staphylococcus spp., Pseudomonas spp., Salmonella spp., Klebsiella spp. and Candida spp. This suggests that these contaminated fomites are capable of giving rise to nosocomial infections. The distribution showed that Pseudomonas spp. had the highest frequency of occurrence (27 \%), followed by Staphylococcus spp. (22\%), then Candida spp. (21\%), Salmonella spp. (16 \%) and then the least occurring microbe was Klebsiella spp. (13\%). Amongst all wards screened, fomites sampled in the theatre showed the lowest level of contamination (4\%). This is probably due to a stricter infection control practice within the theatre as well as restriction to unauthorized personnel as it is only patients undergoing surgery and the healthcare providers that have access into the theatre. It is worthy to note that 6 out of 7 microbes ( $86 \%$ ) isolated from the theatre were Pseudomonas spp. This implies that the infection control strategy such as the disinfectant used in the theatre is not as effective in combating Pseudomonas spp. as it is with other microbes.

Furthermore, the toilet area poses a higher risk of exposure to nosocomial pathogens. The frequency of isolating pathogens were highest from the toilet area namely cistern lever (15\%), toilet seat (14\%), sink (14\%), and sink tap $(12 \%)$. A study has shown that toilet flushing can aerosolize faecal matter thereby contaminating the air and surfaces (16). Besides the surfaces in the toilet area, other surfaces screened for microbial contamination include the doorknob leading into the wards, bedpans, air, and wheelchair handles. All surfaces screened are commonly in contact with patients and healthcare providers at the accident and emergency unit and plastic and burn unit of UPTH. The presence of microbial contamination in these surfaces creates a possibility of transfer of infection.

Several studies have also shown the presence of pathogenic bacteria in various inanimate surfaces within hospitals premises such as medical charts (4), stethoscopes (5), thermometers (6), work surfaces (7), medical equipment (8), medical devices (9), white coats (10), mobile phones (17). Many microbes survive for long periods of time on inanimate surfaces and contribute to challenges associated with the control of hospital-acquired infections. In a systematic review, Kramer and colleagues concluded in their study that nosocomial pathogens may persist on inanimate surfaces for months and can thereby serve as a continuous source of transmission if regular disinfection is not performed (18). The quality and quantity of microbes on surfaces depends on many factors such as type of contaminating microorganism, their ability to form biofilms, and their resistance to disinfectant used. In addition, the nature of the surface and the presence of cracks on surfaces can favour microbial colonization. Furthermore, the quality of microbes on any surface depends on the quality of air. This is because airborne pathogens will inevitably settle on surfaces. Hence, despite adequate cleaning of surfaces, poor air treatment will impact negatively on the cleaning efficiency.

Air quality and inanimate surfaces contribute significantly to many infections acquired in the community and hospital environments. The recent outbreak of the novel 2019 coronavirus disease (COVID-19) has shown high incidence of hospital transmission of the infecting virus (SARS-CoV-2) among healthcare workers (19). Transmission is thought to be mostly through contact with contaminated surfaces and inhalation of airborne droplets. This necessitated the public health recommendation for preventing its spread by maintaining social distancing of at least 6 feet, frequent hand washing and use of facemasks for infected patients and healthcare providers (20). The role of air and surfaces in the transmission of nosocomial infections was highlighted in a study carried out by Wang and co-workers. Healthcare workers directly involved in treatment of COVID-19 patients that wore facemasks and frequently washed their hands were protected more against SARS-CoV-2 infection despite having a significantly higher risk of exposure. As compared with a higher incidence of COVID-19 in other healthcare workers within the same hospital that did not wear facemask, washed their hands occasionally and were not involved in the treatment of COVID-19 patients (21).

Furthermore, the findings of this study revealed a high prevalence of multidrug resistance involving both Gram-negative and Gram-positive bacteria. A very striking observation was the high level of resistance (83\%) to cefoxitin, an indication of the presence of methicillin resistant Staphylococcus aureus (MRSA) in the hospital. S. aureus is a commonly isolated hospital pathogen and the cause of many nosocomial infections (22). Pseudomonas spp. was the most prevalent microbe isolated. It was isolated from every ward sampled including the theatre and poses a huge risk of contracting post-operative surgical infections. Pseudomonas aeruginosa is an opportunistic organism in immuno-compromised individuals and a common nosocomial pathogen implicated in many chronic infections such as pneumonia (23). It exhibits intrinsic resistance to a wide range of antibiotics. The high level of resistant to both anti-pseudomonal 
antibiotics tested calls for public health concern. Both Klebsiella spp. and Salmonella spp. isolated were highly resistant to ceftriaxone, a commonly administered antibiotic in UPTH. Klebsiella spp. is a common hospital pathogen implicated in many respiratory tract and urinary tract infections. Infections caused by Salmonella spp. are often spread through oral-faecal route. Presence of Salmonella spp. is indicative of poor hygiene practices within the hospital environment.

The high incidence of antibiotic resistance in isolated bacteria to commonly prescribed antibiotics is of great public health concern. Frequent antibiotic use in hospitals exerts selective pressure on the development of antibiotic resistant bacteria. It has been shown that increase in antibiotic use increases the development and spread of antibiotic resistance $(24,25)$. As a result, antimicrobial resistance increases number of drugs used in treatment, cost of treatment, duration of treatment, and in severe cases, may be life-threatening if infection is uncontrolled $(2,26,27)$. Hence, effective infection control strategies should be adopted in the hospital such as frequent and deep cleaning (28); use of motion sensors to control cistern levers, sink taps and doorknobs; use of automatic UV room disinfectant systems (29) and the use of antimicrobial coated surfaces such as copper, silver $(30,31)$.

\section{Conclusion}

The study reveals high levels of microbial contamination in inanimate surfaces within the hospital including pathogenic organisms that have the potential to cause hospital-acquired infections. It is recommended that adequate surveillance programs should be set up to monitor and prevent development of hospital-acquired infections.

\section{Compliance with ethical standards}

\section{Acknowledgments}

The authors wish to appreciate the staff of University of Port Harcourt Teaching Hospital for permission to use their facility as a study site and the staff of Department of Pharmaceutical Microbiology and Biotechnology, Faculty of Pharmaceutical Sciences, University of Port Harcourt for permission to use their facility for the research work.

\section{Disclosure of conflict of interest}

The authors declare that there are no conflicts of interest.

\section{References}

[1] WHO. (2002). Prevention of hospital-acquired infections: a practical guide / editors: G. Ducel, J. Fabry and L. Nicolle, 2nd. ed. Geneva, Switzerland : World Health Organization.

[2] Barrasa-Villar JI, Aibar-Remon C, Prieto-Andres P, Mareca-Donate R and Moliner-Lahoz J. (2017). Impact on Morbidity, Mortality, and Length of Stay of Hospital-Acquired Infections by Resistant Microorganisms. Clin Infect Dis, 65(4), 644-52.

[3] Alp E, Coruh A, Gunay GK, Yontar Y and Doganay M. (2012). Risk factors for nosocomial infection and mortality in burn patients: 10 years of experience at a university hospital. J Burn Care Res, 33(3), 379-85.

[4] Chen KH, Chen LR and Wang YK. (2014). Contamination of medical charts: an important source of potential infection in hospitals. PLoS One, 9(2), e78512.

[5] Shiferaw T, Beyene G, Kassa T and Sewunet T. (2013). Bacterial contamination, bacterial profile and antimicrobial susceptibility pattern of isolates from stethoscopes at Jimma University Specialized Hospital. Ann Clin Microbiol Antimicrob, 12, 39.

[6] Worku T, Derseh D and Kumalo A. (2018). Bacterial Profile and Antimicrobial Susceptibility Pattern of the Isolates from Stethoscope, Thermometer, and Inanimate Surfaces of Mizan-Tepi University Teaching Hospital, Southwest Ethiopia. Int J Microbiol, 9824251.

[7] Chaoui L, Mhand R, Mellouki F and Rhallabi N. (2019). Contamination of the Surfaces of a Health Care Environment by Multidrug-Resistant (MDR) Bacteria. Int J Microbiol, 3236526.

[8] Darge A, Kahsay AG, Hailekiros H, Niguse S and Abdulkader M. (2019). Bacterial contamination and antimicrobial susceptibility patterns of intensive care units medical equipment and inanimate surfaces at Ayder Comprehensive Specialized Hospital, Mekelle, Northern Ethiopia. BMC Res Notes, 12(1), 621. 
[9] Singh S, Pandya Y, Patel R, Paliwal M, Wilson A and Trivedi S. (2010). Surveillance of device-associated infections at a teaching hospital in rural Gujarat--India. Indian J Med Microbiol, 28(4), 342-7.

[10] Treakle AM, Thom KA, Furuno JP, Strauss SM, Harris AD and Perencevich EN. (2009). Bacterial contamination of health care workers' white coats. Am J Infect Control, 37(2), 101-5.

[11] Cassini A, Hogberg LD, Plachouras D, Quattrocchi A, Hoxha A, Simonsen GS, et al. (2019). Attributable deaths and disability-adjusted life-years caused by infections with antibiotic-resistant bacteria in the EU and the European Economic Area in 2015: a population-level modelling analysis. Lancet Infect Dis, 19(1), 56-66.

[12] Wang M, Wei H, Zhao Y, Shang L, Di L, Lyu C, et al. (2019). Analysis of multidrug-resistant bacteria in 3223 patients with hospital-acquired infections (HAI) from a tertiary general hospital in China. Bosn J Basic Med Sci, 19(1), 8693.

[13] CLSI. (2016). Performance Standards for Antimicrobial Susceptibility Testing. 26th ed. CLSI supplement M100S. Wayne, PA: Clinical and Laboratory Standards Institute.

[14] Humphries RM, Ambler J, Mitchell SL, Castanheira M, Dingle T, Hindler JA, et al. (2018). CLSI Methods Development and Standardization Working Group Best Practices for Evaluation of Antimicrobial Susceptibility Tests. J Clin Microbiol, 56(4).

[15] Biemer JJ. (1973). Antimicrobial susceptibility testing by the Kirby-Bauer disc diffusion method. Ann Clin Lab Sci, $3(2), 135-40$.

[16] Knowlton SD, Boles CL, Perencevich EN, Diekema DJ, Nonnenmann MW and Program CDCE. (2018). Bioaerosol concentrations generated from toilet flushing in a hospital-based patient care setting. Antimicrob Resist Infect Control, 7, 16.

[17] Debnath T, Bhowmik S, Islam T and Hassan Chowdhury MM. (2018). Presence of Multidrug-Resistant Bacteria on Mobile Phones of Healthcare Workers Accelerates the Spread of Nosocomial Infection and Regarded as a Threat to Public Health in Bangladesh. J Microsc Ultrastruct, 6(3), 165-9.

[18] Kramer A, Schwebke I and Kampf G. (2006). How long do nosocomial pathogens persist on inanimate surfaces? A systematic review. BMC Infect Dis, 6, 130.

[19] Lai X, Wang M, Qin C, Tan L, Ran L, Chen D, et al. (2020). Coronavirus Disease 2019 (COVID-2019) Infection Among Health Care Workers and Implications for Prevention Measures in a Tertiary Hospital in Wuhan, China. JAMA Netw Open, 3(5), e209666.

[20] WHO. (2020). Advice on the use of masks in the context of COVID-19: Interim guidance.

[21] Wang X, Pan Z and Cheng Z. (2020). Association between 2019-nCoV transmission and N95 respirator use. J Hosp Infect, 105(1), 104-5.

[22] Ziebuhr W. (2001). Staphylococcus aureus and Staphylococcus epidermidis: emerging pathogens in nosocomial infections. Contrib Microbiol, 8, 102-7.

[23] Driscoll JA, Brody SL and Kollef MH. (2007). The epidemiology, pathogenesis and treatment of Pseudomonas aeruginosa infections. Drugs, 67(3), 351-68.

[24] Almagor J, Temkin E, Benenson I, Fallach N, Carmeli Y and consortium D-A. (2018). The impact of antibiotic use on transmission of resistant bacteria in hospitals: Insights from an agent-based model. PLoS One, 13(5), e0197111.

[25] Canton R, Horcajada JP, Oliver A, Garbajosa PR and Vila J. (2013). Inappropriate use of antibiotics in hospitals: the complex relationship between antibiotic use and antimicrobial resistance. Enferm Infecc Microbiol Clin, 31 Suppl 4, 3-11.

[26] Friedman ND, Temkin E and Carmeli Y. (2016). The negative impact of antibiotic resistance. Clin Microbiol Infect, 22(5), 416-22.

[27] Struelens MJ. (1998). The epidemiology of antimicrobial resistance in hospital acquired infections: problems and possible solutions. BMJ, 317(7159), 652-4.

[28] Dancer SJ. (2014). Controlling hospital-acquired infection: focus on the role of the environment and new technologies for decontamination. Clin Microbiol Rev, 27(4), 665-90. 
[29] Nerandzic MM, Cadnum JL, Pultz MJ and Donskey CJ. (2010). Evaluation of an automated ultraviolet radiation device for decontamination of Clostridium difficile and other healthcare-associated pathogens in hospital rooms. BMC Infect Dis, 10, 197.

[30] Noyce J0, Michels H and Keevil CW. (2006). Potential use of copper surfaces to reduce survival of epidemic meticillin-resistant Staphylococcus aureus in the healthcare environment. J Hosp Infect, 63(3), 289-97.

[31] Stobie N, Duffy B, Colreavy J, McHale P, Hinder SJ and McCormack DE. (2010). Dual-action hygienic coatings: benefits of hydrophobicity and silver ion release for protection of environmental and clinical surfaces. J Colloid Interface Sci, 345(2), 286-92.

\section{How to cite this article}

Awanye AM and Amrasawore B. (2020). Microbiological assessment of environmental surfaces in a healthcare facility. GSC Biological and Pharmaceutical Sciences, 12(2), 46-55. 